\title{
Stable Strengthening of 990-Gold
}

\author{
David M Jacobson, Martin R Harrison and Satti P S Sangha \\ GEC-Marconi Materials Technology Ltd, Borehamwood, UK
}

The addition of 1 wt $\%$ titanium to gold was found to substantially harden the precious metal and enhance its wear resistance, which makes it attractive for jewellery applications. The enhanced hardening is due to the formation of fine $\mathrm{Au}_{4} \mathrm{Ti}$ precipitates under the appropriate thermo-mechanical treatments. It has been shown that another hardening mechanism can be induced in wire having a diameter of less than $100 \mu \mathrm{m}$, which is stable to heating in air up to $200^{\circ} \mathrm{C}$. These observations are consistent with the formation of a network of titanium oxide inclusions up to $100 \mu \mathrm{m}$ below the free surface, which has been reported elsewhere. New results have indicated that thin foil of $\mathrm{Au}-1 \mathrm{Ti}$, which has been subjected to similar thermo-mechanical processing, exhibits similar properties to those of fine wire of this material. Potential uses for the fine wire and foil are described.

Age-hardened gold containing 1\% $\mathrm{Ti}$ (990-gold) represents one of the most significant new jewellery alloys developed in the last 25 years (1). The fact that gold with up to $1 \%$ base metal content qualifies as ' 24 carat gold jewellery' in much of the Far East has provided the opportunity to choose an addition which substantially enhances the mechanical resilience of gold. Following a systematic study of additives which could be used to precipitation-harden gold at the $1 \mathrm{wt} \%$ level, titanium was identified as the optimum element for this purpose, on both alloy constitution criteria and experimental findings.

The addition of titanium to gold satisfies two important criteria for achieving optimum precipitation hardening.

1 It has a high solid solubility in gold at elevated temperature, which maximises its dissolution into gold.

2 The gold-titanium system has a shallow solvus curve towards pure gold, which enables a significant proportion of titanium to be retained in super-saturated solid solution on quenching. The $\mathrm{Au}_{4} \mathrm{Ti}$ compound, which constitutes the strengthening precipitate, is stable and substantially harder than the gold matrix and so gives rise to a substantial reinforcement $(2,3)$. It has the additional advantage of being rich in gold.

None of the other precipitation forming elements, which belong to Group 13(IIIA), 14(IVA) or the lanthanides, meet the combination of the above criteria as well as does titanium. Hence, Au-1Ti is an optimum choice for a precipitation hardened alloy. It can be endowed with the mechanical properties of low to medium carat gold, whilst retaining the hue and brilliance of pure, 24 carat gold.

The Au-1 Ti alloy is prepared by melting together the constituents in a vacuum induction furnace, and casting the molten alloy into a suitable ingot. It is then precipitation hardened in two stages in the normal manner by first carrying out a solution heat-treatment, involving a heating stage at $800^{\circ} \mathrm{C}$ in a vacuum or inert atmosphere, followed by rapidly cooling the ingot in water. Precipitation hardening is accomplished by heating the ingot of the alloy at a lower temperature, typically at $400^{\circ} \mathrm{C}$, with or without an intermediate cold working stage. A hardness of up to $200 \mathrm{Hv}$ can be achieved by this means. The equivalent tensile strength approaches $750 \mathrm{MPa}$.

The hardness of Au-1Ti in bulk form (defined as having all dimensions larger than $100 \mu \mathrm{m}$ ) as a function of heating time at three different temperatures is shown in Figure 1. The curves are typical for conventional precipitation-hardening behaviour, reaching a maximum hardness and then declining as the precipitates grow and coarsen. The same behaviour has been observed in other recent studies (see Figure 12 , reference 4).

\section{THE ENHANCED STRENGTHENING OF Au-1Ti ACHIEVABLE IN FINE WIRE}

An earlier study of the Au-1Ti alloy in wire form $(5,6)$ demonstrated that a precipitation strengthening 
Foil thickness

Bar after quenching $(6.8 \mathrm{~mm})$

$3.3 \mathrm{~mm}$

$1.7 \mathrm{~mm}$

$750 \mu \mathrm{m}$

$300 \mu \mathrm{m}$

$150 \mu \mathrm{m}$

$60 \mu \mathrm{m}$
Mean hardness, HV

(standard deviation)

$61.2(2.7)$

$82.9(2.2)$

$93.0(2.2)$

$101.7(1.6)$

$105.4(4.5)$

$108.5(7.0)$

III.4 (4.5)

\section{Mean reduction in}

thickness

\section{0}

$51.5 \%$

$75.0 \%$

$89.0 \%$

$95.6 \%$

$97.8 \%$

$99.1 \%$
Table 1 Hardness of Au-1Ti on rolling to $60 \mu \mathrm{m}$ foil

phenomenon is also observed after the material is drawn to a fine wire. In both cases, samples of the material are initially solution treated in a vacuum at approximately $850^{\circ} \mathrm{C}$, water quenched and then cold worked as appropriate, followed by a heat-treatment at a lower temperature to develop maximum strength. It was found that as wire of this alloy was mechanically worked down to a diameter below $100 \mu \mathrm{m}$, a second strengthening mechanism became dominant following the lower temperature heat-treatment. This mechanism is characterised by the stability of mechanical strength to an extended heat-treatment below $400^{\circ} \mathrm{C}$ in air. Thus, whereas, the tensile strength of solution-treated $25 \mu \mathrm{m}$ diameter wire peaks and then drops over time when aged at $400^{\circ} \mathrm{C}$ and above (5), a similar wire heated at $200^{\circ} \mathrm{C}$ in air, develops a strength which stabilizes at a peak value of approximately $900 \mathrm{MPa}$. In other words, fine wire which is heat-treated below $400^{\circ} \mathrm{C}$ does not suffer the overageing that is a characteristic of the classical precipitation-hardening mechanism.

\section{FOIL OF Au-1Ti}

The results obtained on wire suggested that the critical requirements for the stable strengthening mechanism were extensive cold work combined with at least one of the dimensions of the material being less than $100 \mu \mathrm{m}$.

It was decided to investigate cold worked foil in the expectation that similar behaviour might be observed in the alloy when in this form. The Au-1Ti alloy was prepared as before, namely solutiontreatment of a $6.8 \mathrm{~mm}$ diameter bar, which was then rolled down in stages to a foil of $60 \mu \mathrm{m}$.

The hardness of the foil increased as the thickness was reduced by rolling, as shown in Table 1, providing an indication of the progressive increase in cold work that was introduced. The data for foil thinner than $750 \mu \mathrm{m}$ is less precise on account of the increasing difficulty of measuring micro-hardness reproducibly. However, over the thickness range measured, the hardness (HV) increased essentially linearly with reduction in thickness.

Foil that was heat-treated at $400^{\circ} \mathrm{C}$ in air hardened in a similar manner to the fine wire, reaching peak hardness in a timescale of $24-48$ hours, as shown in Figure 1. Further heating at this temperature overaged and softened the foil. However, at $200^{\circ} \mathrm{C}$, the foil developed a maximum hardness after 200 hours and maintained this value even after prolonged heattreatment for 2,000 hours at this temperature. This behaviour is akin to that encountered in fine wire, similarly processed. The peak hardness that could be obtained in the foil was close to $200 \mathrm{HV}$, being consistently higher than that observed in the bulk material, by $-10 \%$. Figure 1 also illustrates another difference between the hardness characteristics of the foil, which is heavily cold-worked, and annealed rod,

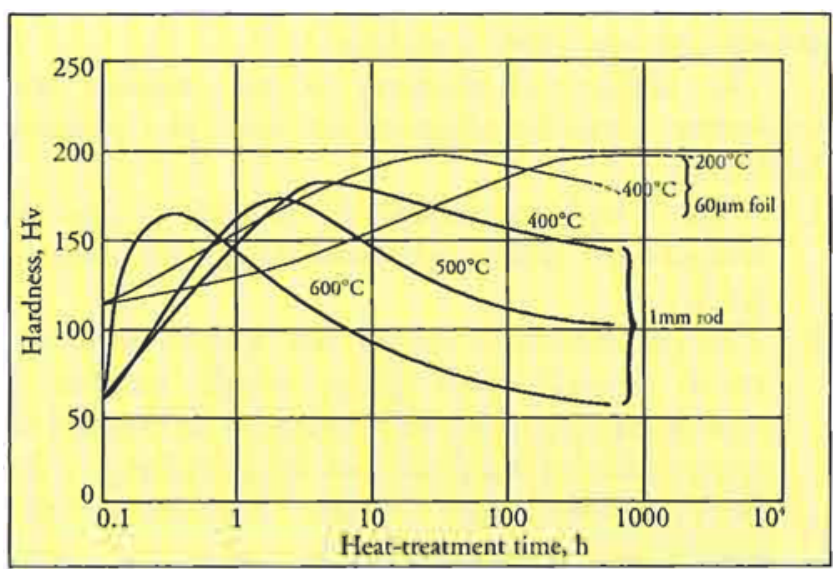

Figure 1 Precipitation hardening characteristics of the Au1 tw $\%$ Ti alloy in bulk form on heat-treatment at 600,500 and $400^{\circ} \mathrm{C}$. Also shown are the hardening characteristics of $60 \mathrm{um}$ thick foil of this alloy at 400 and $200^{\circ} \mathrm{C}$. The bulk material (a $6.8 \mathrm{~mm}$ diameter rod) was solution-treated at $850^{\circ} \mathrm{C}$ and water quenched, prior to the ageing heat-treatment. In the case of the foil this was cold rolled before the ageing, which accounts for the offset in the initial hardness value on the graph. 
which has also been observed by Heger et al (1995). There is a significant increase in the time taken to reach the peak hardness at a given temperature (see Figures 1 and 2). Figure 2 shows that the shift in time to reach peak hardness is similar for $60 \mu \mathrm{m}$ thick foil and $25 \mu \mathrm{m}$ diameter wire.

Although the heating time of 2,000 hours at $200^{\circ} \mathrm{C}$ may be judged insufficiently conclusive in demonstrating oxide strengthening of the foil, the thermo-mechanical characteristics of the foil are so close to those of the wire, where such a strengthening mechanism has been clearly established, that similar behaviour may be reasonably expected.

\section{ANOMALOUS STRENGTHENING MECHANISM}

From the outset, it was proposed that the second strengthening mechanism that had been observed in fine wire was linked to the formation of a dispersed oxide phase, in response to heating in an oxygencontaining atmosphere, notably in air.

The stability of the strength of the wire to extended heating provided an important clue as to its origins, namely the incorporation of a stable oxide within the material which is resilient to heating. Such a mechanism is responsible for the well known zirconia grain-stabilized (ZGS) platinum and gold-platinum alloys (7-9). In these materials, a fine dispersion of stable oxide particles is made to form internally and provides the strengthening. Control of the strengthening in this case is mainly indirect, through the control of grain size and shape in the material. Although titanium can also form a stable nitride, the oxide always forms in preference to the nitride when the metal is heated up to at least $600^{\circ} \mathrm{C}$ in air, and this is reflected in the higher Gibbs free energy of the oxide at $25^{\circ} \mathrm{C}(10)$.

A further clue that supported an oxide strengthening mechanism in the wire was provided by the fact that it was only observed in very thin wire. This was consistent with a limited diffusion path length of oxygen into the alloy, even when this is heavily cold worked. An experiment was undertaken to test whether oxidation is involved in the strengthening of $\mathrm{Au}-1 \mathrm{Ti}$ fine wire (5). A length of Au-1Ti wire that had been drawn down to $25 \mu \mathrm{m}$ was divided into two halves. One of these was solutiontreated at $800^{\circ} \mathrm{C}$, quench-cooled and then aged in an air-ambient atmosphere at $350^{\circ} \mathrm{C}$, while the other length of wire was similarly processed but in a high vacuum throughout. The solution-treatment removed the work hardening produced by the cold drawing to fine wire, which was reflected in a reduction in the strength of the wire that had been heat-treated in a vacuum, to almost that of fully annealed gold. The heat-treatment at $350^{\circ} \mathrm{C}$ was effective in recovering the strength of the wire. By contrast, the length of wire that had been exposed throughout to air did not soften to the same extent and its strength remained unchanged during the subsequent ageing heattreatment at $350^{\circ} \mathrm{C}$. The differences demonstrated the role of oxygen in the stable strengthening of the wire that was processed in air, making oxide strengthening the likely mechanism. While this experiment was only carried out at $350^{\circ} \mathrm{C}$, it is likely that the oxide strengthening mechanism also operates at $200^{\circ} \mathrm{C}$ in heavily work-hardened fine wire.

More recent work by Heger et al (4) has clarified the picture of the strengthening mechanisms that operate in $\mathrm{Au}-1 \mathrm{Ti}$, and more importantly has helped to provide a unifying model of the strengthening mechanisms that occur. They provided a direct demonstration that inclusions of $\mathrm{TiO}_{2}$ nucleate in $\mathrm{Au}$ $1 \mathrm{Ti}$ at grain boundaries and structural defects close to the free surface. Oxide inclusions have been observed in X-ray images of microsections through samples that have been heated in oxygen-containing atmospheres (see Figure 2, reference 4). These oxide inclusions are present in the material, whether in bulk or fine form. The work of Heger et al has indicated that the occurrence of the $\mathrm{TiO}_{2}$ precipitates is dependent on the extent of the defects in the material introduced by cold work and the temperature at which the heat-

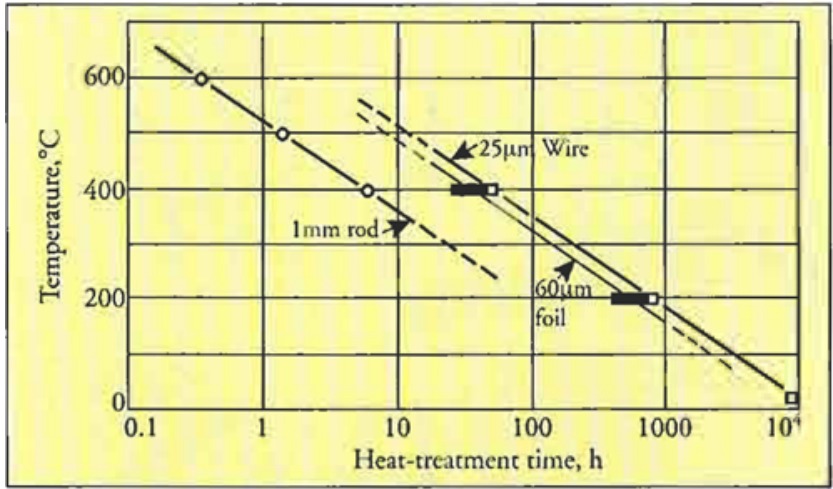

Figure 2 The relationship between ageing heat-treatment time and temperature to achieve peak hardness in the Au1 Iwt\% Ti alloy when in bulk form (Imm diameter rod), 60um thick foil and 25 um diameter wire, showing the similarity in the hardening characteristics of thin foil and fine wire. 
treatment is carried out. The precipitates are normally limited to a layer at the surface, the width of which increases with the temperature and time of the heattreatment and extent of the cold work introduced. Heger et al also examined the dynamics of the oxidation process and have shown a linear relationship between oxygen take-up in $\mathrm{mg} / \mathrm{cm}^{2}$ and exposure time to an oxygen rich atmosphere, at a given temperature, which is consistent with the localization of the oxidation to the near-surface region of the material. While Heger et al did not include consideration of either heavy cold work and the Au-1Ti in a form with small dimensions, their findings are consistent with an important feature of our own results, namely oxidation strengthening being conspicuous in fine wire.

The heavy cold work and resulting high level of defects, coupled with at least one of the dimensions being small $(<100 \mu \mathrm{m})$, ensures that the layer of alloy that can incorporate inclusions of oxide expands to bridge the entire thickness of the material, and this situation is observed when the heat-treatment is carried out below about $350^{\circ} \mathrm{C}$. Then the strengthening characteristics are dominated by the development and stability of the oxide inclusions. However, when the heat-treatment temperature exceeds $350^{\circ} \mathrm{C}$, there is sufficient thermal activation for the titanium within the material to react with the gold to form the intermetallic $\mathrm{Au}_{4} \mathrm{Ti}$ precipitates before it can oxidize, except at or very close to the free surface. The ageing characteristics then follow conventional precipitation strengthening, as in the bulk material. This explanation can be tested by comparing the Gibbs free energy of formation of $\mathrm{Au}_{4} \mathrm{Ti}$ and $\mathrm{TiO}_{2}$ at various

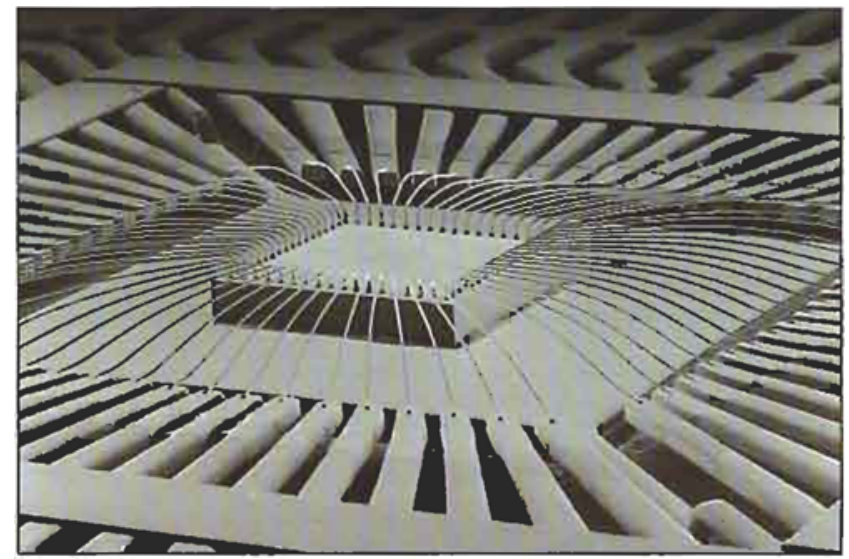

(a) temperatures. However, data for the $\mathrm{Au}_{4} \mathrm{Ti}$ reaction are unavailable at present.

The relative delay in attainment of peak hardness by the foil, compared with the bulk form of Au-1 $\mathrm{Ti}_{\mathrm{i}}$ appears contrary to what one might expect. One possible explanation for this effect, which is also observed in the fine wire (see Figure 2), is that the precipitation strengthening is initially countered by the stress relief of the heavy cold work, and the net effect is a shift in time of peak hardness.

\section{USES OF STRENGTHENED Au-1Ti FOIL AND FINE WIRE}

In the thermo-mechanical processing that was carried out on thin foil and fine wire of $\mathrm{Au}-1 \mathrm{Ti}$, the thinning down was accomplished before the strengthening heattreatment was undertaken and this enabled oxygen to penetrate the entire volume during the heat-treatment at temperatures lower than $350^{\circ} \mathrm{C}$ and oxidize the titanium. It is this process that gives rise to thermally resilient strengthening. However, this is not achievable in the material in bulk form because of the relatively low penetration depth of oxygen in gold $(<50 \mu \mathrm{m})$, even when considerable cold work damage is introduced. Therefore, bulk artefacts such as items of jewellery in Au-1Ti could only be oxide-strengthened by first mechanically reducing the material to flake or a similar fine form, oxide strengthening it in that condition, and subsequently consolidating the material into the required shape by a technique such as hot pressing it at a temperature lower than $350^{\circ} \mathrm{C}$. This is

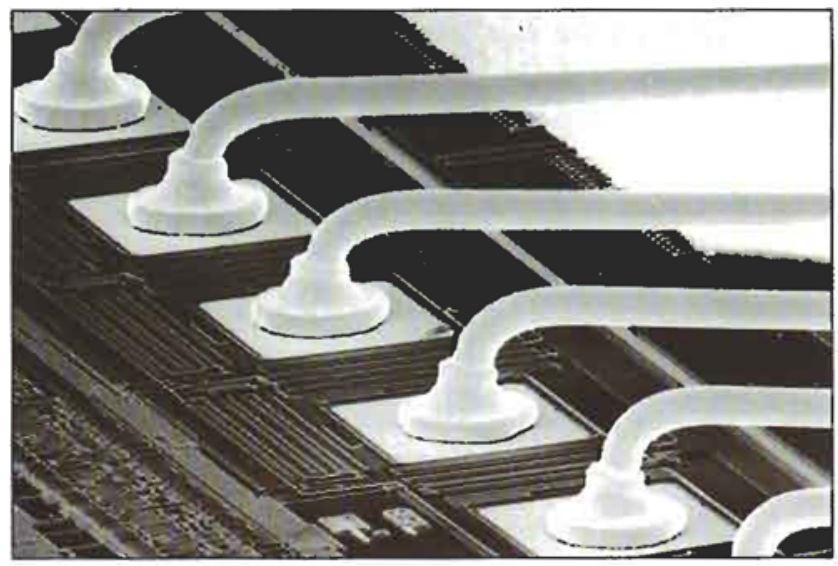

(b)

Figure 3 Scanning electron microscope (SEM) photographs showing 25um gold wire interconnections to semiconductor devices: (a) general view of wire interconnections between a silicon chip and a lead frame in a package.

(b) close-up view, showing ball bonds to pads on a chip.

(Courtesy of Kulicke \& Soffa Industries) 
Step 1:

A spark or small flame

is used to locally melt

the end of the wire so

as to form a spherical

ball that is

approximately twice

the diameter of the wire

Step 2:

The ball is

thermosonically welded

to an aluminium

metallized pad on the

semiconductor

Step 3:

A loop of wire is

formed as the bonding capillary moves across to the contact pad of the device package or circuit board

Step 4:

The wire is

thermosonically welded to the gold metallized pad of the package

Step 5:

A sharp edge on the tool is used to cut the wire, leaving a length protruding from the capillary that is of the correct length to form the next ball

Figure 4 Schematic illustration of the steps involved in making a single interconnection using bondwire (after reference 5).

technically possible but would impose cost penalties against which the benefits, principally of enhanced hardness would need to be balanced. It is not clear at present whether this approach would be economically viable. Oxide-strengthened foil lends itself to applications requiring highly resilient conductive membranes.

A more attractive application is the use of Au-1Ti in fine bondwire for electronic interconnection, which originally prompted this study. The stable oxide strengthening ensures that the boosted mechanical properties of the wire are resilient to subsequent thermal processing involved in electronics manufacture, which make it ideal for interconnects produced by both thermosonic ball-wedge and thermocompression wedge bonding (5).

The metals customarily used for this application are gold, aluminium and occasionally copper. Subpercentage additions of other elements, including cobalt, iron, calcium and tin (11) are usually made to boost the mechanical properties of the wire by solidsolution strengthening. This choice has been determined by several different requirements, not least of which is the ability to prepare essentially continuous lengths of fine wire (down to $15 \mu \mathrm{m}$ in diameter and even less), by drawing. Gold is particularly favoured on account of its good drawing characteristics, resistance to corrosion, high electrical conductivity and the relative ease with which it can be bonded onto confined metal pads in an air ambient environment by standard micro-welding techniques. For these reasons, more than $90 \%$ of the wire bonds produced are made with gold wire.

Three methods are used for making wire connections between microelectronic devices and headers on the packages which provide a link to the external circuitry. These are ultrasonic, thermocompression and thermosonic bonding. In ultrasonic bonding the wire is firmly pressed down on the bond pad of the circuit board using a wedge tool. A burst of ultrasonic vibration is applied to the wedge, resulting in a cold weld between the wire and the bond-pad. In thermocompression bonding, heat rather than ultrasonic energy is used to accomplish the weld, with the bonding surface being heated to $350^{\circ} \mathrm{C}$. The most widely used method of wire bonding, however, is thermosonic bonding, which uses both heating and ultrasonic energy to form the welds. Wire loops are formed using a ball bond on the pad of the device and a stitch bond on the header. The ball bond has the advantage of enabling the wire to be vertically attached to the bond pad of the device and so accommodate a high density of connections. The stitch joint is made almost tangentially onto a larger bonding area. A typical wire-bonded device is shown in Figure 3(a) and a close-up view of ball bond is illustrated in Figure 3(b). The sequence of steps involved in making a 
single wire interconnection is shown in Figure 4.

The versatility of wire interconnection is likely to ensure that its use will continue and even grow in the foreseeable future. In the last three decades, demand for gold bond-wire has increased by roughly $20 \%$ per annum and this phenomenal growth is set to continue. Far from challenging this trend, new developments in electronics assembly are instead encouraging expansion of the market for bondwire. Thus, the rise of multichip modules (MCMs), whereby silicon chips are mounted directly on a silicon substrate in a package, is spurring demand for fine wire. Generally, MCMs are designed with large numbers of input/output connections, with over a thousand interconnections to the external circuitry from a single module, as in a Pentium processor. This high density of interconnections demands that the contact pads have as small a footprint as possible and an extremely small (< $100 \mu \mathrm{m})$ centre-to-centre distance (i.e. pitch) between the bond pads. The only interconnection technique that is capable of meeting such fine pitch requirements is ball bonding, as detailed above (12).

Some modifications have been carried out to optimize the performance of Au-1Ti wire for the interconnection application. An addition of an outer coating of pure gold has been shown to boost the ac conductivity of the wire. This makes use of the skin effect, whereby the ac current is largely confined close to the outer surface, which is high conductivity pure gold. The gold cladding also promotes the formation of ball terminations when heating the tip of the wire by spark discharge or with a flame, a crucial step towards producing a thermosonic bond to the contact pad of the requisite circuit. Further fine-tuning requires the involvement of bonding machine manufacturers to address optimization of the heating pattern and design of the capillary in the bonder, aimed at achieving a suitable profile of the loop of wire on the circuit board.

\section{ACKNOWLEDGEMENTS}

The support provided by the World Gold Council for this work is gratefully acknowledged. Dr Giles Humpston of GEC-Marconi Materials Ltd, Caswell, is acknowledged for his contribution to the work on the fine wire of Au-1Ti.

\section{ABOUT THE AUTHORS}

Dr Jacobson manages The Materials Processing Group at the Hirst Division of GMMT Ltd, and possesses wide experience in metal joining and bonding methods, having graduated as a physicist and obtained his doctorate in Materials Science. He has worked in the joining of gold for ten years and made many original contributions to the field.

Dr Harrison obtained his doctorate from Oxford in Solid State Chemistry and carried out post-doctoral research at Cornell and Cambridge Universities on materials undergoing metal-insulator transitions. He has spent the last decade investigating the synthesis and properties of the new high temperature superconducting ceramics. Recent interests include the development of electronics packaging materials, metallizations and solders for microwave devices.

Dr Sangha is an electrical engineer whose doctorate is in Materials Science. He has applied his knowledge to the assessment of gallium arsenide semiconductor systems and the development of low melting point brazes for joining a wide range of aluminium engineering alloys before investigating the gold systems described herein.

\section{REFERENCES}

1 A.M. Tasker, Aurum, 1988, 34, 62

2 J.L. Murray in 'Binary Alloys and Phase Diagrams', Volume 1, ed. T.B. Massalski et al, ASM, Metals Park, USA, 1986, p. 324

3 R. Wagner and R. Kampmann in 'Phase Transformations in Materials', Volume 5, ed. R.W. Cahn et al, VCH, Weinheim, Germany, 1991, p. 213

4 D. Heger, K. Jenkner, P. Klimanek, D. Bergner; and Ch. J. Raub, Mat.-wiss., u. Werkstofftech, $1995,26,507$

5 G. Humpston and D.M. Jacobson, Gold Bull., $1992,25,132$

6 G. Humpston and D.M. Jacobson, Gold Technology, 1992, 6, 5

7 G.L. Selman, J.G. Day and A.A. Bourne, Platinum Metals Rev., 1974, 18, 46

8 A.E. Heywood and R.A. Benedek, Platinum Metals Rev., 1982, 26, 98

9 R.B. McGrath and G.C. Badcock, Platinum Metals Rev., 1987, 31, 8

10 R. H. Perry and D.W. Green, 'Perry's Chemical Engineer's Handbook', 6th Edition, McGrawHill, New York, USA, 1984

11 S. Tomiyama and Y. Fukui, Gold Bull., 1982, 15, 43

12 V. McGinty, Electronic Packaging and Production, October 1995, 42 